\title{
Efeitos sistêmicos e síndrome de retirada em tomadores crônicos de corticosteróides
}

\author{
S. FAIÇAL, M.H. UEHARA \\ Disciplina de Endocrinologia - Departamento de Medicina, Universidade Federal de São Paulo - Escola Paulista de Medicina, São \\ Paulo, SP.
}

UNITERMOS: Corticosteróide. Eixo adrenocortical. Síndrome de Cushing. Síndrome de retirada.

KEY WORDS: Corticosteroid. Adrenal axis. Cushing syndrome. Withdrawal syndrome.

A indicação do corticosterói de na terapêutica da artrite reumatóide, por Philip Hench, em 1949, foi um dos marcos dentro da medicina. O glicocorti cóide é assim denominado pelos seus conhecidos efeitos sobre o metabolismo dos carboidratos; porém, este hormônio possui outras ações além desta que é a mais lembrada ${ }^{1}$. Essas propriedades são mediadas por receptores intracelulares denominados receptor de glicocorticóide2; entretanto, algumas delas são mediadas por meio de receptores mineral ocorticóides ${ }^{3}$. O modo pelo qual o glicocorticóide atinge seu receptor parece ser devido à provável difusão passiva por meio da membrana lipídica, não necessitando de transporte específico para tal ${ }^{2}$.

A utilização prolongada dos corticosteróides leva à síndrome de Cushing iatrogêni ca, caracterizada pela desfiguração cosmética (moon face, giba dorsal, estrias), ganho de peso com acúmulo de gordura centripetamente, redução da tol erância a carboidratos, fragilidade vascular, pele fina, miopatia e fraqueza muscular, hipertensão arterial, osteoporose, maior suscetibilidade a infecções, alterações psiquiátricas, e outros. A maior diferença desta síndrome exógena, em relação ao hipercortisolismo endógeno, constitui na maior ação mineralocorticóide existente neste último, resul tando em mais hipertensão arterial e, ocasi onalmente, hipocalemia e hirsutismo e/ou virilização, principalmente quando secundário a tumores adrenais. Além disso, alguns efeitos menos comuns, como a hipertensão intracraniana benigna, necrose avascular óssea e glaucoma, teriam maior relação com a síndrome de Cushing iatrogênica do que com o hipercortisolismo endógeno 4 .

Os efeitos colaterais de uma mesma dose de corticosteróide são heterogêneos entre os indivíduos de uma população; os motivos para esta heterogeneidade são, provavelmente, a cinética ou as diferentes concentrações plasmáticas das proteínas carreadoras desses fármacos ${ }^{4}$. Essas diferenças podem ser observadas em alterações da depuração, como sua diminuição encontrada em hepatopatias, nefropatias, terapia estrogênica, uso de cetoconazol, alguns antiinflamatórios e em idosos, ou sua aceleração secundária ao uso de fenitoína, fenobarbital e rifampicina ${ }^{5,6}$.

Variados esquemas terapêuticos têm sido propostos com o intuito de minimizar os efeitos del etérios advindos de seu uso crônico, dos quais o mais efetivo é seu emprego em dias alternados, que, praticamente, não influi sobre o eixo hipotálamohipófise-adrenal e a velocidade de crescimento das crianças. No entanto, a incidência de osteoporose não é reduzida, apesar dessas tentativas ${ }^{5,7,8}$. Cabe realçar que a diferença observada entre os esquemas está na dependência de fatores como dose, horário, ti po da droga etempo de uso dos corticói des.

\section{EFEITOS NO METABOLISMO INTERMEDIÁRIO}

O metabolismo intermediário é influenciado globalmente pelos glicocorticóides, não apenas sobre os glicídios, como sugere seu nome, mas também sobre protídios e lipídios.

A alteração mais comum no metabolismo dos hidratos de carbono devido ao excesso de glicocorticóides é tendência à diminuição da tolerância, podendo levar, em al guns casos, à hi pergli icemia de jejum. A intensidade desse distúrbio dependerá da reserva pancreática de cada indivíduo e é conseqüente ao aumento da gliconeogênese hepática, que resulta: 1 ) da maior atividade de sua cascata enzimática; 2) em maior afluxo de substratos periféricos; e 3) da habilidade de outros hormôni os em estimular esse processo ${ }^{10}$. Os mecanismos citados anteriormente são justificados em termos fisiopatológicos, respectivamente, por: aumento da atividade das enzimas fosfoenol pi ruvato carboxi quina- 
se e, possivelmente, glicose-6-fosfatase; incremento do afluxo de aminoáci dos (principalmente alanina), de glicerol e de lactato advindos do tecido periférico, dentre eles o adiposo e o muscular; e uma sensibilização hepática aos efeitos do glucagon e catecolaminas ${ }^{9,10}$.

A resistência insulínica, presente nesses casos e que contribui para a intolerância aos hidratos de carbono, pode ser vislumbrada pela mensuração dos níveis de insulina basal e estimulada, levando, a Iongo prazo, à hiperplasia das células beta-pancreáticas $^{11}$.

A distribuição diferenciada da gordura em pacientes em uso crônico de corticosteróides é quase que constante. Os motivos pel os quais isso ocorre podem ser devidos à perda de tecido celular subcutâneo de modo dissociado, tendo como resultado uma redução em extremi dades e um acúmulo centripetamente. Desse modo, a variabilidade dos tecidos em responder à ação de glicocorticóides (catabólica) e da insulina (anabólica) deve ser a causa da heterogeneidade da gordura corporal ${ }^{12}$.

A alteração lipídica observada no hipercortisolismo baseia-se na elevação de lipoproteínas de baixa densidade (VLDL e LDL), tendo como conseqüência um incremento dos níveis séricos de colesterol e triglicérides; a base disso, provavelmente, é multifatorial, sendo as causas mais observadas a influência na síntese do VLDL, produção de ácidos graxos e atividade da lipase endotelial hepática ${ }^{13}$.

A síntese protéica corporal encontra-se reduzida em tomadores crônicos de corticosteróides, sendo documentada pelo balanço nitrogenado negativo observado nesses indivíduos. A inflluência sobre a síntese de proteínas está fundamentada na ação desses fármacos sobre a expressão do DNA e RNA celular. Quanto ao RNA, há aumento de sua síntese no fígado e inibição de sua produção em tecidos periféricos; em relação ao DNA, ocorre aumento de sua degradação em nível detecidos periféri $\cos ^{9,14,15}$.

\section{EFEITOS NO BALANÇO HIDROELETROLÍTICO}

\section{1) Cálcio}

O metabolismo do cál cio é al terado pela ação dos gl icocorticóides em diferentes sítios, como intestino, rim e unidade de remodelação óssea.

A influência mais evidente em nível intestinal seria a diminuição da absorção desse íon; um dos mecanismos defendidos para esse efeito seria a inibição do transporte ativo transcelular, que pode ser explicada pela diminuição da síntese de proteínas ligadoras de cál cio, diminuição da produção de cál cio pela mitocôndria, estimulação da bomba NaK-ATPase, e outros ${ }^{16}$. Entretanto, estudos em ca- mundongos demonstraram uma correlação inversa entre dose do hormônio e metabolismo do cál cio pel o duodeno, isto é, baixas doses de gl i cocorticóides aumentam, enquanto altas doses reduzem a absorção do íon.

De modo semel hante, a corticoterapia influencia negativamente o metabolismo do cálcio em nível renal. I nicialmente, os gl icocorti cóides aumentam a excreção urinária de cál ci ${ }^{17}$, provavel mente, devido à redução da sua reabsorção tubular renal ${ }^{18}$. Essa ação se deve à maior carga filtrada de cálcio (devido ao aumento da reabsorção óssea ou ao efeito vasodilatador dos corticóides, levando ao aumento do fluxo renal sanguíneo e da taxa de filtração glomerular) ou a uma redução das proteínas ligadoras de cál cio, dependente de vitamina D, presentes nas células tubulares ${ }^{19}$. E sse efeito renal associado ao intestinal induzirá, conseqüentemente, ao hiperparatiroidismo secundário.

E, por último, em relação à uni dade de remodelação óssea, tem-se demonstrado ação tanto na reabsorção quanto na formação. No que tange à primeira, estudos histomorfométricos sugerem um aumento da sua atividade conseqüente ao hi perparatiroidismo secundári $0^{20}$ e, também, segundo alguns estudos em ratos, um efeito estimulante dos gl icocorticói des sobre a função e a produção, transitória, dos osteoclastos ${ }^{21,22 ;}$; enquanto na segunda notou-se uma redução em torno de $30 \%$ da quantidade de osso reposto em cada cicl o (explicada pela diminuição da vida média dos osteoblastos ativos devido a ação inibitória dos corticóides na sua replicação e diferenciação) ${ }^{23}$.

Além dos efeitos di retos exerci dos pel os gl i cocorticói des na remodelaçào óssea, também se observa um efeito indireto, não menos importante, devido à sua ação no eixo hi potálamo-hi pófise-adrenogonadal. Sabidamente, os hormôni os sexuais são potentes reguladores de remodelação óssea. Assim, os glicocorticóides, por bloquearem, em nível hipofisário, a resposta do LH ao estímulo do LHRH e, também, do ACTH ao CRH, reduzirão a produção de estrógenos ou testoterona gonadal e andrógenos adrenais (de particular importância em mulheres menopausadas, tratadas com corticói de, quando os níveis estrogênicos dependem da conversão de androstenediona no teci do adi poso) ${ }^{24,25}$. Além desse efeito central, em nível ovariano e testicular, observa-se inibição de produção de estrógeno ou testosterona pelas células da granulosa ou de Leydig, respectivamente ${ }^{26}$.

\section{2) Sódio e potássio}

A excreção de sal e água encontra-se elevada quando do uso de glicocorticói des conseqüente aos 
seus efeitos na produção do peptídeo atrial natriurético e no fluxo gl omerular renal. Como exemplo disso, a dexametasona, um esterói de com ação predominantemente glicocorticóide em preferência à mineralocorticóide, produz intensa natriurese, contrastando com aqueles retentores de sal ${ }^{27}$.

E m relação ao potássio, o que se observa é que em altas doses ocorre hi pocalemia, que é resultado da ação mineralocorticóide e/ou de caliurese transitória decorrente do aumento do fluxo urinário. Apesar disso, as concentrações de potássio plasmático podem estar normais ou apenas levemente dimunuídas por estarem contrabalançadas pelo aumento dos seus níveis circulantes provenientes do catabolismo protéico celular.

A alcalose metabólica, nos indivíduos tomando corti costeróides, resulta de el evada excreção ácida renal, com mínimas influências sobre o pH urinário, devido ao incremento da excreção de fosfatos, por bloqueio na reabsorção, e de amônia, por aumento de produção ${ }^{28}$.

\section{EFEITOS NA PRESSÃO ARTERIAL SANGUÍNEA}

Hipertensão arterial desenvolve-se em $70-80 \%$ dos pacientes com síndrome de Cushing endógeno e em $15-20 \%$ em indivíduos em uso crônico de corticosteróides, e os mecanismos bási cos para que isso ocorra são a retenção salina e o aumento da reatividade vascular. Em relação à hiperatividade vascular, contribui nesse sentido a ação na musculatura lisa vascular e das células endoteliais, o aumento da atividade de substâncias vasoativas, dentre as quais catecol aminas ${ }^{29}$, e a supressão da síntese e/ou ação de vasodilatadores endógenos que, somados a ação direta em nível cardíaco, resul tam em el evação dos níveis pressóri cos. E mbora controversa, a redução da síntese de prostaglandinas, potentes vasodilatadores e principal produto do ácido araquidônico em artérias e veias, que vem ao encontro com o achado de produção di minuída de prostaglandina urinária em pacientes em corticoterapia prolongada ${ }^{30}$, favorece o predomínio das substâncias vasoconstritoras.

Além dos já citados, outro mecanismo envolvido na fisiopatol ogia da hipertensão arterial é o sistema renina-angiotensina-aldosterona. Nesse eixo, os corti costerói des atuam aumentando os ní veis da renina 326 e dos substratos da renina 314 e, somados a isso, existe um incremento da atividade da enzima conversora responsável pela geração de angiotensina $\mathrm{II}^{31}$. A pesar disso, os niveis de renina são normais ou levemente el evados na terapia prolongada, e tais concentrações são inapropriadamente altas em face da hi pertensão arterial vigen- te, inferindo uma responsividade à terapêutica com inibi dores da enzima de conversão de reninaangiotensina nesses indivíduos ${ }^{30}$.

\section{EFEITOS NAS RESPOSTAS IMUNOLÓGICA E INFLAMATÓRIA}

A freqüência e severidade das infecções el evamse devido ao uso crônico de glicocorticóides decorrentes da supressão das respostas imunológica e inflamatória ${ }^{9,32}$.

E m relaçãoà supressão imunológica, não se sabe muito a respeito, mas sugere-se que o hipercortisolismo inibi ria a resposta auto-imune contra antígenos produzidos por tecidos lesados ${ }^{33}$; o achado de que corticóides suprimem reação de leucócitos autól ogos sem afetar a reação al ogênica é compatível com essa hipótese ${ }^{32}$.

Alterações da resposta inflamatória são decorrentes da inibição da produção e/ou atividade de agentes vasoativos, do movimento de leucócitos e da função de cél ulas imunocompetentes no local da inflamação, tais como macrófagos, linfócitos B eT, células polimorfonucleares e mononucleares e a liberação de prostaglandinas, interleucinas, cininas e proteases (por exemplo: ativador de plasminogênio).

A redução da síntese de prostaglandinas ocorre devi do a ação da macrocortina ou lipoproteína, cujo nível está elevado pela corticoterapia e que tem função de inibir a fosfolipase $A$; outro efeito seria o bl oquei o das ações da bradicinina, também reguladora da síntese de prostaglandinas; os esteróides ainda bloqueiam a produção de histamina e substâncias responsáveis pela anafilaxia, como os leucotrienos ${ }^{34,35}$.

A administração de glicocorticóides em humanos causa linfocitopenia, monocitopenia e eosinopenia. As ações nos linfócitos e monócitos são máximas dentro de 4 a 6 horas após a administração, retornando à normalidade após 24 a 48 horas e persistindo com a administração contínua. Esses efeitos são devidos à redistribui ção de células movimentando-se da circulação para dentro de compartimentos corporais (medula óssea, baço, linfonodos e ducto torácico) ${ }^{32,36}$. Contrariamente, em rel ação aos neutrófil os, ocorre uma el evação da sua concentração, atingindo o pico em 4 a 6 horas, e tal fato é conseqüente à produção acelerada pela medula óssea, meia-vida aumentada e remarginalização reduzida ${ }^{9,32,35}$.

Nolocal do processo inflamatório ocorre redução dos níveis de leucócitos polimorfonucleares, macrófagos e linfócitos, notadamente por duas horas $^{9,33}$. Tais ações são devidas, em parte, ao fato de 
que gl i cocorticói de inibe o fator ativador de plasminogênio, afetando o acúmul o dessas cél ulas no local da lesão, sendo este seu maior mecanismo de ação antiinflamatória ${ }^{32,35}$.

\section{EFEITOS NO SISTEMA REPRODUTOR}

N este sistema, os efeitos inibi tórios são observados predominantemente com glicocorticóides em altas doses.

A diminuição da concentração plasmática de testosterona encontrada em pacientes masculinos resulta da inibição da produção de LH e a ações diretas nos testículos, al ém da potencialização do feedback negativo ${ }^{37}$ exercido por esse andrógeno na produção das gonadotrofinas. Por outro lado, em pacientes femininos, ocorre supressão dos níveis plasmáticos de LH basal e após estímulo com LHRH, o que não ocorre com o FSH, dos níveis plasmáticos de estrógeno e progesterona, da ovulação e do início da puberdade; entretanto, paradoxalmente, nas célul as adi posas observa-se um aumento dos níveis da aromatase, induzindo conversão de andrógenos a estrógenos ${ }^{38}$.

\section{EFEITOS EM OUTROS SISTEMAS}

\section{1) Gastrointestinal}

A corticoterapia prolongada induz a leve incremento da produção de ácido clorídrico pela mucosa gástrica; entretanto, não existe aumento na incidência de úlceras pépticas, de acordo com dados recentes, exceto naqueles indivíduos recebendo antiinflamatórios não-esteróides concomitantemente ${ }^{39}$.

\section{2) Oculares}

A pressão intra-ocular, em indivíduos suscetíveis, apresentará uma elevação decorrente, provavel mente, de alteração na drenagem trabecular do humor aquoso, particularmente naqueles com glaucoma de ângulo aberto ${ }^{9,40}$. A longo prazo e em altas doses, pode ocorrer a ligação covalente dos esteróides às proteínas do cristalino, induzindo a formação de catarata ${ }^{40,41}$.

\section{3) Sistema nervoso central}

A barreira hematocefálica tem sua permeabilidade modulada a outras substâncias pel os gl i cocorticóides, o que torna possível seu uso na terapia antiedema cerebral ${ }^{42}$.

Várias alterações do humor são descritas no hipercorti sol ismo, e, inicialmente, existe um bemestar geral, em oposi ção ao observado na síndrome de Cushing endógena, na qual mais comumente os pacientes se apresentam deprimidos. Em relação ao sono, existe tendência à redução da fase REM e incremento da fase $\mathrm{II}^{43}$.

\section{SÍNDROME DE RETIRADA}

Duas situações são extremamente delicadas ao manusearmos os corticosteróides: seus efeitos colaterais e a chamada "síndrome de retirada", consistindo em sinais e sintomas decorrentes da diminuição ou retirada total do corticóide.

A introdução da corti coterapia implica, durante seu uso, na ocorrência dos efeitos colaterais acima descritos; entretanto, sua suspensão é, também, potencialmente danosa devido à possibilidade de doi s eventos: a síndrome de retirada e a insuficiência adrenocortical secundária (supressão do eixo hipotálamo-hipófise-adrenal - HHA). A primeira, descrita por Amatruda ${ }^{44}$, caracteriza-se por anorexia, letargia, náuseas, artralgias, fraqueza, perda de peso, descamação da pele e febre, sendo marcada pela integridade do eixo HHA, estabelecido por vários índices, além de se documentar a ausência de recrudescência da doença de base.

Os mecanismos pel os quais a síndrome de retirada ocorre ainda são desconhecidos; entretanto, duas hipóteses são possíveis: 1) variação da concentração sérica devido à mudança de altas para baixas doses de gl i cocorti cói de, induzi ndo sintomatologia semelhante à insuficiência adrenal secundária; ou 2) relativo grau de resistência aos glicocorticói des cursando com status hi pocortisolêmico.

A classificação em quatro subtipos, para síndrome de retirada, foi proposta por Dixon ${ }^{45}$, sendo caracterizadas, respectivamente, como:

Tipo I - evidências clínicas, bioquímicas e hormonai s da supressão do eixo HHA, demonstradas de manei ra rigorosa;

Tipo II - recrudescência dos sintomas da doença de base pela qual a corticoterapia foi instalada, com normal resposta do eixo HHA;

Tipo III - presença dos sintomas característicos da síndrome, porém com resposta normal do eixo HHA esem recrudescência da doença de base e cujos sintomas mel horam com o retorno da administração do glicocorticóide acima da dose fisiológica (25mg de cortisona ou equivalente). Esse tipo pode ser definido como dependência, seja esta física ou psicológica;

Tipo IV - presença de demonstrada insuficiência do eixo HHA, porém sem sintomas da síndrome ou da doença de base.

Desse modo, a situação do paci ente no momento da retirada do corticosteróide será extrememente variável, dependendo do esquema e da duração da terapia medicamentosa. 


\section{RECUPERAÇÃO DO EIXO HIPOTÁLAMO- HIPÓFISE-ADRE NAL}

A supressão do eixo hipotálamo-hipófise-adrenal em pacientes em corticoterapia é bem estabelecida; anormalidades nos níveis basais de cortisol sérico e em resposta ao estímulo com ACTH exógeno ${ }^{46}$ ou ao stress, como a hipoglicemia, já têm sido demonstradas. Melby ${ }^{47}$ já dizia: "supressão do eixo hipotál amo-hi pófise-adrenal é um dos mais prevalentes e potencialmente danosos riscos induzidos pela corticoterapia". Entretanto, correlação entre parâmetros clínicos e hormonais da supressão do eixo hipotálamo-hipófise-adrenal não tem sido demonstrada regularmente, enquanto quea admi nistração de gl i cocorti cói des por longo período mostra uma variação importante em suprimir a resposta do eixo HHA ${ }^{48}$. Assim, essa variabilidade entre pacientes, no que diz respeito à recuperação do eixo, após a suspensão do medicamento, é dependente da dose e do tempo (vários estudos já documentaram esse fenômeno).

Livanou ${ }^{49}$ demonstrou que a maioria dos pacientes que utilizavam 7,5 a 10mg/dia de prednisona ou equivalente possuía níveis normais de cortisol basal após um mês de suspensão da medicação; no entanto, a resposta do eixo ao stress (por exemplo, hipoglicemia induzida por insulina) só estaria recuperada totalmente após um ano de suspensão do hormônio; demonstrou, ainda, que pacientes recebendo menos de 7,5mg/dia de prednisona ou equivalente tinham níveis de cortisol basal e recuperação do eixo ao stress mais rápido que os que recebiam mais de $10 \mathrm{mg} / \mathrm{dia}$, principalmente naqueles em uso inferior a 18 meses.

Outros estudos em pacientes fazendo uso de 50 a $60 \mathrm{mg} / \mathrm{dia}$ de prednisona por cinco dias ${ }^{50}$ ou $40 \mathrm{mg} /$ dia por 21 dias $^{51}$ demonstraram uma transitória supressão do eixo HHA, com recuperação total em 5 a 10 dias após a interrupção da droga.

Graber $^{52}$ avaliou, prospectivamente, a recuperação do eixo HHA em tomadores crônicos e demonstrou que: um mês após suspensão do corticóide, os níveis séricos de cortisol basal e pós-estímulo com ACTH exógeno eram subnormais, assim como os níveis de ACTH endógeno; após 2 a 5 meses, os níveis de ACTH eram normais ou até el evados, com níveis de cortisol basal e pós-estímulo com ACTH exógeno permanecendo abaixo dos valores normais; após 6 a 9 meses, o nível de cortisol basal era normal, enquanto que a resposta ao ACTH exógeno ainda permanecia subnormal; após 9 meses, tanto os níveis basal e pós-estímulo com ACTH eram normais.

Os pacientes tomando glicocorticóide em dias alternados ou em dose única têm níveis suprimidos de cortisol basal, porém possuem resposta normal ou quase normal ao stress.

Portanto, os corti costeróides, amplamente utilizados por médicos generalistas e de diferentes especialidades, são drogas com alto potencial de morbi-mortal idade, desde que não adequadamente manuseados. Por isso, sempre ao introduzir esses medicamentos, devemos ter em mente os seguintes princípios: utilizá-los o menor tempo possível, existência de outra alternativa terapêutica menos deletéria, associação com outra droga que diminua as doses necessárias dos corticosteróides, o esquema em dias alternados é viável como opção e, por último, prevenir efei tos colaterais se o indivíduo já é suscetível.

\section{REFERÊNCIAS BIBLIOGRÁFICAS}

1. Gaunt R. History of adrenal cortex. In Greep RO, Astwood EB. Handbookof physiology: Endocrinology. Washington, DC, Americam Physiological Society, 1975, section 7, vol 6, p 1.

2. Baxter J D, Tyrrel J B. The adrenal cortex. In Felig P, Baxter J D, Broadus AE et al. Endocrinology and metabolism. New York, McGraw-Hill Book, 1988; 511-650.

3. Funder J W, Pearce PT, Smith R et al. Mineralocorticoid action: target tissue specificity is enzyme, not receptor, mediated. Science 1988; 242: 583-5.

4. Tyrrel J B, Baxter J D. Glucocorticoid therapy. In Felig P, Baxter J D, Broadus AE et al. Endocrinol ogy and Metabolism. New York, McGraw-Hill Book, 1988; 788-817.

5. Tsay SY, Carlstedt-Duke J, Weigel NL et al. Molecular interactions of steroid hormone receptor with its enhancer element: evidence for receptor dimer formatiom. Cell 1988; 55: 361-9.

6. Gustavson LE, Benet LZ. Pharmacokinetics of natural and synthetic glucocorticoids. In Anderson DC, Winter J SD. The adrenal cortex. Stoneham, Mass, Butterworth Publishers, 1985; 235-79.

7. Ellis EF. Corticosteroid regimens in pediatric pratice. Hosp Pract 1984; 19:143-51.

8. Schurmeyer TH, Tsokos GC, Avgerinos PC et al. Pituitaryadrenal responsiveness to corticotropin-realising hormone in patients receiving chronic, alternate day glucocorticoid therapy. J Clin Endocrinol Metab 1985; 61: 22-7.

9. Baxter J D. Glucocorticoid hormone action. In Gill GN. Pharmacology of adrenal cortical hormones. Oxford, Pergamon, 1979; 67.

10. Exton J H. Regulation of gluconeogenesis by glucocorticoids. In Baxter J D, Rousseau GG. Glucocorticoid hormone action. New York, Springer-Verlag, 1979; 535.

11. Lenzen S, Bailey CJ . Thyroid hormones, gonadal and adrenocortical steroids and the function of the islets of Langerhans. Endocrinol Rev 1984; 5: 411.

12. Fain J N. Inhibition of glucose transport in fat cells and activation of lipolysis by glucocorticoids. In Baxter J D, Rousseau GG. Glucocorticoid hormone action. New York, Springer-Verlag, 1979; 7.

13. Taskinen M-R, Nikkila EA, Pelkonen $R$, Sane T. Plasma liporpoteins, lipolytic enzymes, and very low density lipoprotein triglyceride turnover in Cushing's syndrome. J Clin Endocrinol Metab 1983; 57: 619. 
14. Baxter JD. Mechanisms of glucocorticoid inhibition of growth. Kidney Int 1978; 14: 330.

15. Loeb J N. Corticosteroids and growth. N Engl J Med 1976; 295: 547.

16. Lukert BP, Raisz LR. Glucorticoid-induced osteoporosis: pathogenesis and management. Ann Intern Med 1990; 112: 352-64.

17. Hahn TJ, Halstead LR, Strates B, Imbimbo B, Baram DT. Comparison of subacute effects of oxazacort and prednisol one on mineral metabolism in man. Calcif Tissuel nt 1980; 30: 109-15.

18. Reid IR, Ibbertson HK. Evidence for decreased tubular reabsorption of calcium in glucocorticoid treated asthmatics. Hormone Res 1987; 27: 200-4.

19. Delorme AC, Danan J L, Mathieu H. Biochemical evidence for the presence of two vitamin $D$ dependent calcium-binding proteins in mouse kidney. Biochem Chem 1993; 258: 1.87884.

20. Meunier PJ, Bressot C. Endocrine influences on bone cells and bone remodeling evaluated by clinical histomorphometry. In Parsons J A (ed). Endocrinol ogy of cal cium metabolism. New York, Raven Press, 1982; 445-65.

21. Reid IR, Katz J M, I bbertson HK, Gray DH. The effects of hydrocortisone, parathyroid hormone, and the bisphosphonate, APD, on bone resorption in neonatal mouse calvaria. Calcif Tissue Int 1986; 38: 38-43.

22. Gronowicz G, McCarthy MB, Woodiel F, Raisz LG. Effects of corticosterone and parathyroid hormone on formation and resorption in cultured fetal rat parietal bones [Abstract] Am Soc Bone Min Res 1988; 3(suppl 1): 5.114.

23. Dempster DW, Arlot MA, Meunier PJ. Mean wall thickness and formation periods of trabecular bone packets in corticosteroid-induced osteroporosis. Calcif Tissue Int 1983; 35: 410-7.

24. Sarakura M, Takebe K, Nakagowa S. Inhibition of Iuteinizing hormone secretion induced by synthetic LRH by long term treatment with glucocorticoids in human subjects. J Clin Endocrinol Metab 1975; 40: 774-9.

25. Crilly RG, Cawood M, Marshall DH, Nordin BEC. Hormonal status in normal, osteoporotic and corticosteroid treated post menopausal women. J R Soc Med 1978; 71: 733-6.

26. Hsueh AJ, Erickson GF. Glucocorticoid inhibition of FSH induced oestrogen production in cultured rat granulosa cells. Steroids 1978; 32: 639-48.

27. Gardner DG, Hane S, Trachewsky D, Schenk D, Baxter J D. Atrial natriuretic peptide mRNA is regulated by glucocorticoids in vivo. Biochem Biophys Res Commun 1986; 139: 1.047.

28. Freiberg J M, Kinsella J , Sacktor B. Glucocorticoids increase the $\mathrm{Na}-\mathrm{H}$ exchange and decrease the $\mathrm{Na}$ gradient-dependent phosphate-uptake systems in renal brush border membrane vesicles. Proc Natl Acad Sci USA 1982; 79: 4.932

29. Nichols NR, McNally M, Campbell J H, Funder J W. Overlapping but not identical protein synthetic domains in cardiovascular cells in response to glucocorticoid hormones. Hypertension 1984; 2: 663.

30. Saruta T, Suzuki H, Handa M et al. Multiple factors contribute to the pathogenesis of hypertension in Cushing's syndrome. J Clin Endocrinol Metab 1986; 52: 275.

31. Friedland J, Setton C, Silvestein E. Angiotensin converting enzyme induction by steroids in alveolar macrophages in culture. Science 1977; 197: 44.

32. Parillo J E, Fauci AS. Mechanisms of glucocorticoid action on immune processes. Annu Rev Pharmacol Toxicol 1979; 19: 179.

33. Craddock CG. Corticosteroid-induced lymphopenia, immunosuppression and body defense. Ann Intern Med 1978; 88: 546.

34. Munck A, Guyre PM, Holbrook NJ . Physiological functions of glucocorticoids in stress and their relation to pharmacological actions. Endocrinol Rev 1984; $5: 25$.

35. Fahey J V, Guyre PM, Munck A. Mechanisms of anti-inflammatory actions of glucocorticoids. In Weissman G. Advances in inflammatory research, vol 2. New York, Raven, 1981; $\mathrm{p} 21$.

36. Altman LC, Hill J S, Hairfield WM, Mullarkey MF. Effects of corticosteroids on eosinophil chemotaxis and adherence. J Clin Invest 1981; 67: 28.

37. Vreeburg J TM, de Greef WJ, Ooms MP, van Wouw P, Wever RFA. Effects of adrenocorticotropin and corticosterone on the negative feedback action of testosterone in the adult male rat. Endocrinology 1984; 115: 977.

38. Simpson ER, Ackerman GE, Smith ME, Mendelson CR. Estrogen formation in stromal cells of adipose tissue of womem: indution by glucocorticosteroids. Proc Natl Acad Sci USA 1981; 78: 5.690.

39. Messer J, Sacks HS. Association of adrenocorticosteroids therapy and ulcer disease. N Engl J Med 1983; 309; 21.

40. Polansky J R, Weinreb RM. Anti-inflammatory agents: steroids as anti-inflammatory agents. In Sears ML. Handbook of experimental pharmacology. New York, Springer-Verlag, vol 69, 1984; 459.

41. Manabe S, Bucala R, Cerami A. Nonenzymatic addition of glucocorticoids to lens proteins in steroid-induced catarats. J Clin Invest 1984; 74: 1.803.

42. Long J B, Holaday J W. Blood-brain barrier: endogenus modulation by adrenalcortical function. Science 1985; 27: 1.580.

43. Gilin J C, J acobs LS, Fram DH, Snyder F. Acute effect of a glucocorticoid on normal human sleep. Nature 1972; 237: 398.

44. Amatruda J r TT, Hurst MM, D'E sopo ND Certain endocrine and metabolic facets of the steroid withdrawal syndrome. J Clin Endocrinol Metab 1965; 25:1.207.

45. Dixon RB, Christy NP. On the various forms of corticosteroid withdrawal syndrome. Am J Med 1980; 68: 224.

46. Faiçal S, Kater CE. Standardization and clinical applications of the rapid and prolonged ACTH stimulation tests in patients with primary and secondary adrenal insufficiency. Rev Ass Med Brasil 1991; 37: 1.321-8.

47. Melby J C. Sistemic corticosteroid therapy: pharmacology and endocrinologic considerations. Ann Intern Med 1974; 81: 505.

48. Christy NP. The clinical significance of pituitary-adrenal suppression by exogenous corticosteroids. J Chronic Dis 1973; 26: 261

49. Livanou T, Ferriman D, J ames VHT. Recovery of hipothalamo-pituitary-adrenal function after corticosteroid therapy. Lancet 1967; 2: 856-9.

50. Streck WF, Lockwood DH. Pituitary recovery following short-term supression with corticosteroids. Am J Med 1979; 66: 910.

51. Webb J, Clarck TSH. Recovery of plasma corticotrophin and cortisol levels after a three-week course of prednisolone. Thorax 1981; 36: 22-4.

52. Graber AL, Ney RL, Nicholson WE et al. Natural history of pituitary-adrenal recovery following long-term suppression with corticosteroids. J Clin Endocrinol Metab 1965; 25: 11-6 